\title{
Maxillary calcifying epithelial odontogenic tumor with sinus and buccal vestibule extension: a case report and immunohistochemical study
}

\author{
Cristina Munteanu ${ }^{1}$, Daniel Pirici ${ }^{2 *}$, Alex Emilian Stepan ${ }^{3}$, Adrian Camen $^{1}$ and Claudiu Margaritescu ${ }^{3}$
}

\begin{abstract}
Background: Calcifying epithelial odontogenic tumor (CEOT) is a rare benign neoplasia, locally aggressive, that tends to invade bone and adjacent soft tissues. This case report describes the thirteenth known case of CEOT with maxillary sinus extension and the second one that also involves the buccal vestibule mucosa with peculiar histopathological and immunohistochemical data.

Case presentation: Here we report the case of a 45-year-old female with a CEOT diagnosed and treated at the Oral \& Maxillofacial Surgery Department, County Clinical Emergency Hospital of Craiova, Romania. The clinical and imaging investigation revealed an intraosseous tumor developed from the left posterior maxilla with maxillary sinus and buccal vestibule mucosa extension. Histopathology found an epithelium-rich CEOT variant, but with scattered S100 positive clear cells, focal small rounded cementum-like deposits and areas with some degree of nuclear pleomorphism. The immunohistochemical investigations emphasised its local aggressiveness behavior with involvement of multiple molecular mechanisms that underlie tumor invasiveness. A subtotal maxillectomy was performed followed by defect reconstruction.

Conclusions: We discuss the relevant clinicopathological features of an aggressive rare case of CEOT with maxillary sinus extension and buccal vestibule mucosa involvement. The immunohistochemical study suggests its utility in attempting to assess the degree of local tumor aggressiveness and thus in adopting the most efficient therapeutic attitude.
\end{abstract}

Keywords: Calcifying epithelial odontogenic tumor, Immunohistochemistry, Maxillary sinus, Tumor aggressiveness

\section{Background}

Calcifying epithelial odontogenic tumour (CEOT) is a rare benign epithelial odontogenic neoplasia that is characterized by the presence of amyloid-like material that may become calcified [1].

The first cases were reported by Thoma and Goldman [2] in 1946 as an "adenoid adamantoblastoma", and in 1971 the term "calcifying epithelial odontogenic tumor" was generally accepted and adopted by the WHO [3].

It is one of the least frequent odontogenic tumors, its incidence ranging between 0.4 and 3\% [4]. Although it is

\footnotetext{
* Correspondence: danielpirici@yahoo.com

${ }^{2}$ Department of Research Methodology, University of Medicine and

Pharmacy Craiova, Petru Rares 2, Craiova 200349, Romania

Full list of author information is available at the end of the article
}

a benign tumor, sometimes can be locally aggressive infiltrating the surrounding jaw bones structures $[5,6]$, and even vital structures such as the brain [7]. Furthermore, in English literature it was reported a general recurrence rate ranging from 15 to $30 \%$, mostly due to inadequate management $[4,8,9]$. On the other hand, malignant transformation appears to be a rare event, with less than 10 cases reported so far $[10,11]$.

We report here a case of intraosseous CEOT developed from the left posterior maxilla with maxillary sinus and buccal vestibule mucosa extension. A comprehensive immunohistochemical study was performed concerning the local aggressive behavior of this tumor. A written informed consent was obtained from the patient for research and publication purposes. 


\section{Case presentation History}

A 45 year old female presented to our institution with a diffuse swelling of the left maxilla which caused a mild tumefaction of the left cheek and obliteration of the buccal vestibule, left cheek pain during chewing with auricular and temporal irradiation, and masticatory disorders. The patient reported the onset of symptoms about 3 weeks before, but the exact duration of the swelling is not known. However, the patient remembered that about 3 years ago she was complaining of pain in the molar region of left maxilla and she addressed to her dentist. Without X-ray examination it was decided for extraction of the 2nd molar which presented palatal ectopia, but without caries and no abnormal mobility. Personal or family records were not significant, but noteworthy is that she worked about 10 years as an industrial dyer.

\section{Local physical examination}

Extraoral examination revealed a mild diffuse swelling of the left cheek, most obvious at the posterior side of the zygomatic region. It was painless and hard in consistency on palpation. Intraoral examination revealed a diffuse swelling extending from the maxillary left first premolar to the tuberosity and retromolar regions that obliterated the buccal vestibule (Fig. 1a). The overlying mucosa was stretched but intact. On palpation, at the level of maxillary alveolar process the swelling was hard and painless but became fluctuating and slightly tender in the retromolar region.

\section{Radiographic and CT findings}

Orthopantomogram showed a radiolucent lesion involving the left maxillary tuberosity, alveolar process, and the maxillary sinus with erosion of lateral wall and floor of the sinus (Fig. 1b). On computed tomography scan it was noticed an expansile, radiolucent lesion of the left maxilla (about $4 \mathrm{~cm}$ in diameter) with scattered areas of calcification which completely obliterated the left maxillary sinus (Fig. 1c). The scan showed tumor extension and involvement of the alveolar process (behind the first premolar with buccal cortical thinning, erosion and invasion of the soft tissue from retromolar region), maxillary sinus (with erosion of lateral and nasal walls, and floor of the sinus) and palatine process.

\section{Management}

Based on history, clinical and imaging findings, a provisional diagnosis of benign locally aggressive odontogenic neoplasm of the left maxilla was considered. Under
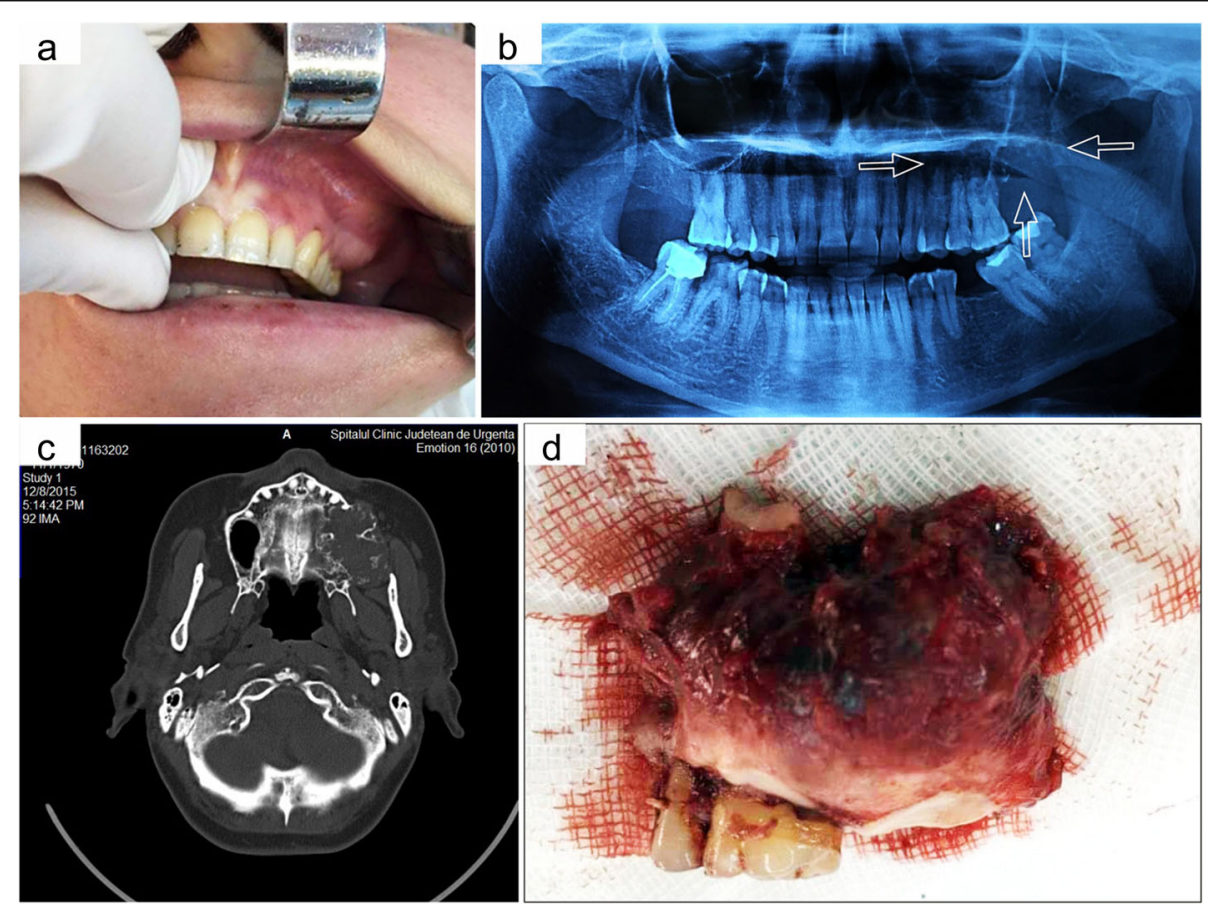

Fig. 1 Clinico-radiological and gross pathological features of the tumor. a Intraoral view of the tumor with expansion on upper left buccal vestibule obliterations. b Orthopantomogram showing osteolytic image of left maxilla with few foci of calcifications. $\mathbf{c}$ Axial CT demonstrates radiolucency of the left maxilla that completely obliterated the maxillary sinus and involvement of the alveolar process with erosion of the cortical plate and invasion of the adjacent soft tissue. $\mathbf{d}$ Post-operative view of the lesion after surgical exposure. Gross features of the surgical specimens including the alveolar process with corresponding teeth 
general anesthesia, a subtotal maxillectomy procedure was performed through Dieffenbach's modification of WeberFergusons incision followed by defect reconstruction.

\section{Gross examination}

The surgical specimen included almost the entire left maxilla, respectively the entire zygomatic process, the distal alveolar process with corresponding teeth, and limited area of the frontal and palatal processes, measuring $4.5 \times 4 \times 3 \mathrm{~cm}$ in total (Fig. 1d). The tumor eroded the floor and anterolateral wall of the maxillary sinus, occupying the entire left maxillary sinus being adherent to the lining mucosa but without its ulceration. Also, this tumor distorted the left alveolar process starting from the second bicuspid tooth up to the retromolar area, destroying the left maxillary tuberosity and distal to the third molar tooth becoming adherent to the vestibular mucosa but without its ulceration. The palatal process was partially involved but without palatal fibromucosa invasion. The tumor itself was relatively well defined, with smooth surface and firm in consistency. On cut section it appeared as solid, whitish gray with various amounts of calcification, and with sandy-like consistency.

\section{Histopathological examination}

The tumor was composed of variable amounts of polyhedral eosinophilic epithelial cell islands, cords and strands in a fibrous stroma. These neoplastic cells had well-defined boundaries, intercellular bridges in focal areas and some degree of nuclear pleomorphism, including few bizarre nuclei (Fig. 2a). Between cells and within tumoral stroma, there was a conspicuous homogeneous eosinophilic acellular material that stained positive for Congo red (Fig. 2b). This material was confirmed as amyloid by examination in polarized light after Congo red staining, with the deposits exhibiting the characteristically apple-green birefringence (Fig. 2c). Some of the small round-shaped amyloid-like entities undergone calcification and only a few of them presented Liesegang rings. We also noticed the presence of areas with accentuated nuclear pleomorphism (Fig. 2d), some multinucleated giant cells (Fig. 2e), scattered S100 positive clear cells (Fig. 2f), and few clear cells with intracytoplasmic PAS-positive granules (glycogen). Altogether, the tumor did not raise the suspicion of another origin, as for example a primary or metastatic intraosseous squamous cell carcinoma. In some areas, between neoplastic proliferations were also observed small rounded cementum-like deposits (Fig. 2g). The tumor proliferations penetrated the cortical plates of maxillary bone invading the connective tissue of the maxillary sinus mucosa and the vestibular mucosa but without involvement of the lining epithelium (Fig. 2h, i).

\section{Immunohistochemical findings}

The polyhedral neoplastic epithelial cells were diffusely cytoplasmic immunoreactive for CK 5/6 and CK19, while the clear cells were negative for these epithelial markers, exhibiting a nuclear and cytoplasmic positivity for the anti-S100 protein. Also the tumor polyhedral cells had an intense nuclear reactivity for p63, and with the cytoplasm slightly positive for vimentin, but negative for $\alpha$-smooth muscle actin.

In order to explain its extremely aggressive behavior we investigated tumor cell immunoreactivity for a number of markers related to tumor invasiveness, as listed in Table 1. Thus, we observed expression of matrix metalloproteinases (MMP)-1, MMP-2, MMP-3, and MMP-9 mainly in the nuclei of tumor cells, while for MMP-3 and MMP-9 the immunoreactivity was also present in the cytoplasm of tumor cells and in the amyloid deposits (Fig. 3a, b). In addition, collagen IV reactivity was detected as a linear pattern around the tumor islands, sheets and nests but with variable thickness along the tumor tissue with discontinuities at the advancing edge (Fig. 3c).

Investigation of markers involved in cell adhesion showed a positive reaction with prevailing membranous pattern in the tumor cells for $\mathrm{E}-, \mathrm{N}$ - and P-cadherin, Integrin $\beta 1$ and Beta-catenin. However, as a peculiarity of the tumor advancing edge, where small groups or cords of infiltrating tumor cells were present, the staining pattern became also cytoplasmic for all cadherins, Integrin $\beta 1$ and Beta-catenin (Fig. 3d), and even nuclear for N- (Fig. 3e) and P-cadherin. In these areas the membranous immunoreactivity decreased and at least for E-cadherin we noticed an increased cytoplasmic colocalization with vimentin (Fig. 3f).

Investigation of other markers involved in the epithelialmesenchymal transition process revealed mostly a nuclear reactivity of tumor cells for Twist 1 and Slug 1 (Fig. 3g) that seemed to be more intense at the advancing edge. Also, the chemokine receptor -4 (CXCR4) reactivity was also noticed in tumor cells with membranous, cytoplasmic and even nuclear pattern (Fig. 3h) Moreover, the podoplanin tumor cell reactivity, with a membranous pattern, was more obvious at the advancing edge, at the periphery of tumor proliferations (Fig. 3i). However the Ki-67 labeling index in tumor cells was less than 3\% and without any significant difference regarding the tumor topography.

A final diagnosis of intraosseous CEOT with maxillary sinus and buccal vestibule submucosa extension was made on the basis of the above findings. After 12 months of follow-up, the patient did not present any clinical or radiographic evidences of recurrence.

\section{Discussion}

CEOT is a rare benign odontogenic neoplasm of epithelial origin with locally aggressive behavior that so far does not exceed 200 reported cases [10]. In our experience this is 


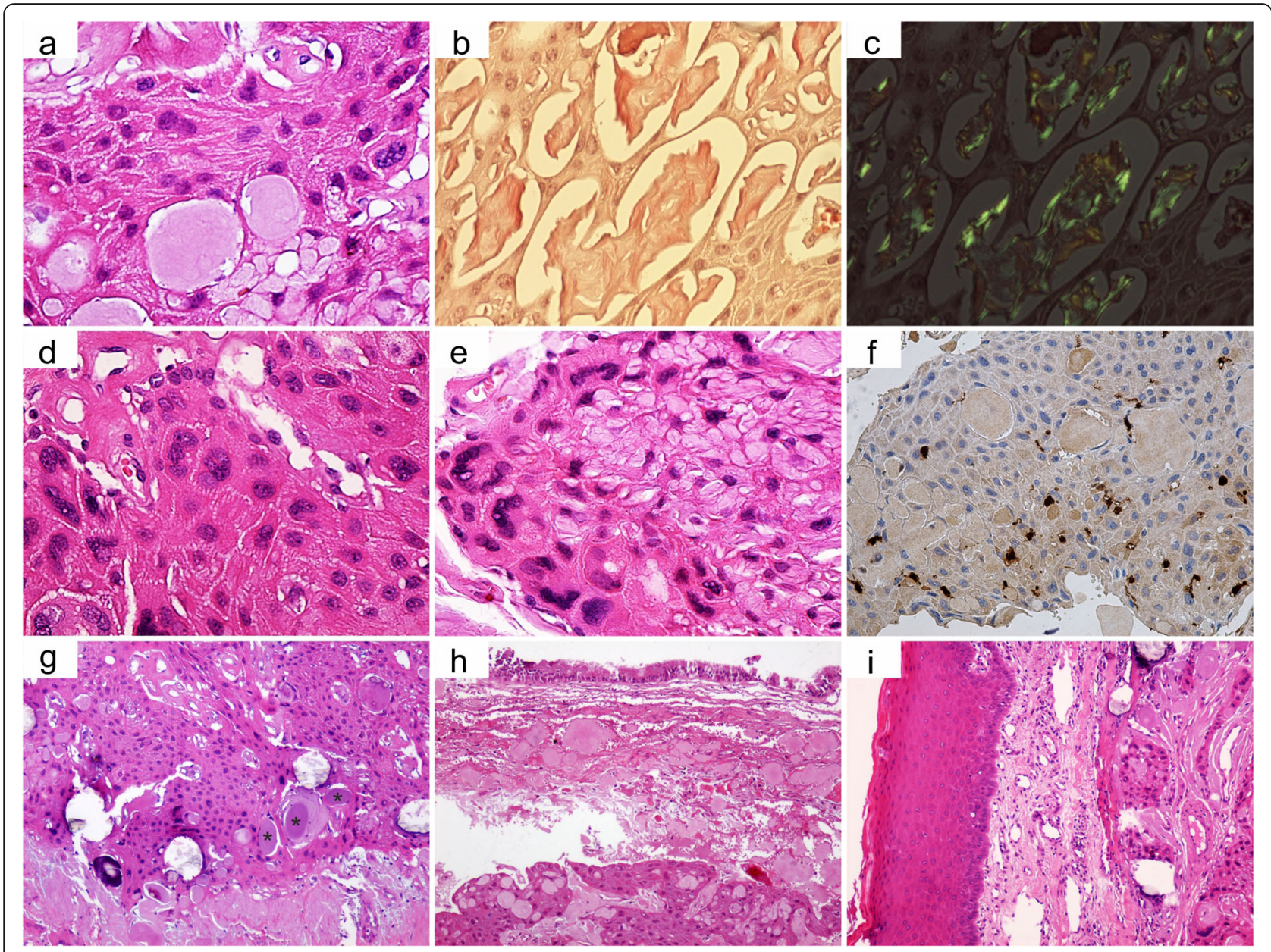

Fig. 2 The main histomorphological features of the tumor. a The tumor was composed of polyhedral neoplastic cells with intercellular bridges and some degree of nuclear pleomorphism (hematoxylin and eosin [H\&E]; original magnification $\times 40$ ). $\mathbf{b}$ Homogeneous eosinophilic acellular material between neoplastic proliferations that stained positive for Congo red (Congo red stain; original magnification $\times 40$ ). $\mathbf{c}$ Intercellular deposits with apple-green birefringence on polarized light examination of the Congo red stained sample (original magnification $\times 40$ ). $\mathbf{d}$ Tumor areas with nuclear pleomorphism $\left(H \& E_{\text {; }}\right.$ original magnification $\left.\times 40\right)$. e Tumor areas with nuclear pleomorphism and multinucleate giant cells $\left(H \& E_{;}\right.$ original magnification $\times 40$ ). $\mathbf{f}$ Scattered S100 positive clear cells between polyhedral neoplastic cells (immunostaining, original magnification $\times 20)$. $\mathbf{g}$ Tumor comprises areas with cementum-like material $\left(^{*}\right)(H \& E$; original magnification $\times 10)$. $\mathbf{h}$ Tumor invasion of the maxillary sinus mucosa without involvement of the lining epithelium (H\&E; original magnification $\times 10$ ). $\mathbf{i}$ Tumor invasion of vestibular mucosa without involvement of the lining epithelium ( $\mathrm{H} \& \mathrm{E}$; original magnification $\times 10)$

the second case of CEOT from a total of 231 cases of odontogenic tumours diagnosed in our hospital since 1990. The general epidemiological profile reported in the literature for this odontogenic tumor shows a mean age at presentation of 40 years, with no gender predilection and mandible as the most commonly affected jaw bone [1]. Similarly to other authors [4], our results indicated the intermediary layer of the enamel organ as the most probable origin for this type of odontogenic tumor.

One of the peculiarities of the presented case is its intraosseous development in the left posterior maxilla with extraosseous involvement of maxillary sinus and buccal vestibule mucosa. Reviewing the literature, we found other 12 cases of CEOT with an extension to the maxillary sinus, which are summarized in Table 2. Thus, the present case is the thirteenth CEOT with maxillary sinus extension and the second one that also involved the buccal vestibule mucosa. These aggressive CEOT tumors seem to develop at a median age of 35 years with no gender predilection, in association or not with impacted teeth and no predilection for the right or left maxilla [4, 12-22]. Histopatologically they had the same features as a conventional COET, only one case being reported with the clear cell variant and another one with the cystic variant. A particular feature of the present case was the presence of scattered S100+ clear cells and deposits of cementum-like material. In more than half of these cases, CEOT evolved extraosseous with extension 
Table 1 Characteristics of the antibodies utilised in the study

\begin{tabular}{|c|c|c|c|c|}
\hline Antibody name & Clone & Company & Dilution & Staining pattern \\
\hline MMP1 & $3 \mathrm{~B} 6$ & Santa Cruz Biotechnology, Inc. Dallas, USA & $1: 25$ & Nuclear \\
\hline MMP2 & $2 \mathrm{C} 1$ & Santa Cruz Biotechnology & $1: 25$ & Nuclear \\
\hline MMP3 & 1B4 & Santa Cruz Biotechnology & $1: 25$ & $\begin{array}{l}\text { Nuclear, cytoplasmic, } \\
\text { amyloid }\end{array}$ \\
\hline MMP9 & $2 \mathrm{C3}$ & Santa Cruz Biotechnology & $1: 25$ & $\begin{array}{l}\text { Nuclear, cytoplasmic, } \\
\text { amyloid }\end{array}$ \\
\hline E-cadherin & $\mathrm{NCH}-38$ & Dako, Glostrup Denmark & $1: 30$ & Membranous, cytoplasmic \\
\hline N-cadherin & $6 \mathrm{G} 11$ & Dako & $1: 30$ & Membranous, nuclear \\
\hline P- cadherin & $\mathrm{H}-105$ & Santa Cruz Biotechnology & $1: 30$ & Membranous, cytoplasmic, nuclear \\
\hline Integrin $\beta 1$ & $4 \mathrm{~B} 7 \mathrm{R}$ & Santa Cruz Biotechnology & $1: 30$ & Membranous (lost in some areas), cytoplasmic \\
\hline Beta-catenin & $\beta$-catenin-1 & Dako & $1: 100$ & Membranous, cytoplasmic \\
\hline Vimentin & SP20 & Thermo Fisher Scientific, Waltham, USA & $1: 200$ & Cytoplasmic \\
\hline Twist 1 & 10E4E6 & Leica Biosystems, Wetzlar, Germany & $1: 1000$ & Nuclear \\
\hline Slug 1 & $1 \mathrm{~A} 6$ & Novus Biologicals, Abingdon, UK & $1: 50$ & Nuclear, cytoplasmic \\
\hline CXCR4 & polyclonal & Thermo Scientific & $1: 500$ & Membranous, cytoplasmic, nuclear \\
\hline Podoplanin & D2-40 & Dako & $1: 50$ & Membranous \\
\hline Collagen IV & CIV 22 & Dako & $1: 50$ & Basement membranes \\
\hline Ki-67 & MIB-1 & Dako & $1: 50$ & Nuclear \\
\hline Cytokeratin $5 / 6$ & D5/16 B4 & Dako & $1: 50$ & Cytoplasmic \\
\hline Cytokeratin19 & b170 & Leica Biosystems & $1: 150$ & Cytoplasmic \\
\hline P63 & 7JUL & Leica Biosystems & $1: 25$ & Nuclear \\
\hline S100 & polyclonal & Dako & $1: 500$ & Cytoplasmic, nuclear \\
\hline Actin (Smooth Muscle & $1 \mathrm{~A} 4$ & Dako & $1: 40$ & Cytoplasmic \\
\hline Actin, Smooth Muscle & polyclonal & Thermo Scientific & $1: 100$ & Cytoplasmic \\
\hline
\end{tabular}

in the adjacent soft tissues, and to the neighboring natural cavities (oral cavity, orbit, nasal fossae, and ethmoidal air cells) [4, 12-22].

It is well know that this odontogenic tumor can be locally aggressive, and exhibit up to $15 \%$ recurrence rates, especially in cases treated by conservative techniques [9].

Throughout time several prognostic factor have been proposed to predict the behavior of such tumors and to estimate their recurrence risk. Thereby, clinical features such as size, anatomic site, and health status of the patient have been shown to influence prognosis of these tumors [4, 12]. It is widely accepted that maxillary CEOTs tend to be more aggressive and involve much easier the surrounding vital structures than mandibular tumors. As it is also mentioned in the literature, and as well as in our case, amyloid deposits were not very abundant, with calcifications being even less present, a fact that might suggest a more aggressive behavior [23].

Also, CEOTs with clear cells seem to be more aggressive, with a higher rate of recurrence (22\%) and frequently associated with cortical bones perforation [24]. In the present case we showed that few $\mathrm{S} 100+$ cells were scattered between eosinophilic polygonal neoplastic cells. This reactivity reflects the dendritic nature of these cells and their clear cell morphology could be an effect of tumor microenvironment on the Langerhans cells migrating in the tumor as a result of the host's immune response [25]. Such morphological changes could represent a mechanism by which tumours can escape immune surveillance and gain a more aggressive biologic behavior.

For a better understanding of the molecular mechanisms that underlie the aggressiveness of this odontogenic tumor we planned to investigate the expression patterns of a number of markers known to be involved in tumor invasiveness.

First we have checked the tumor cells reactivity for the main MMPs (MMP-1, -2, -3, -4) known to be involved in extracellular matrix remodeling. Thus we noticed a tumor nuclear reactivity for all MMPs but with high intensity especially for MMP-3 and MMP-9, which were also expressed in the cytoplasm and within amyloid deposits. Henriques et al. [26] found a higher MMP9 expression both in tumor cells and stroma, for keratocystic odontogenic tumors and ameloblastomas, that might justify their locally aggressive behavior. The nuclear tumor cell expression for the all 4 investigated MMPs reported by us might also be linked to new functional 


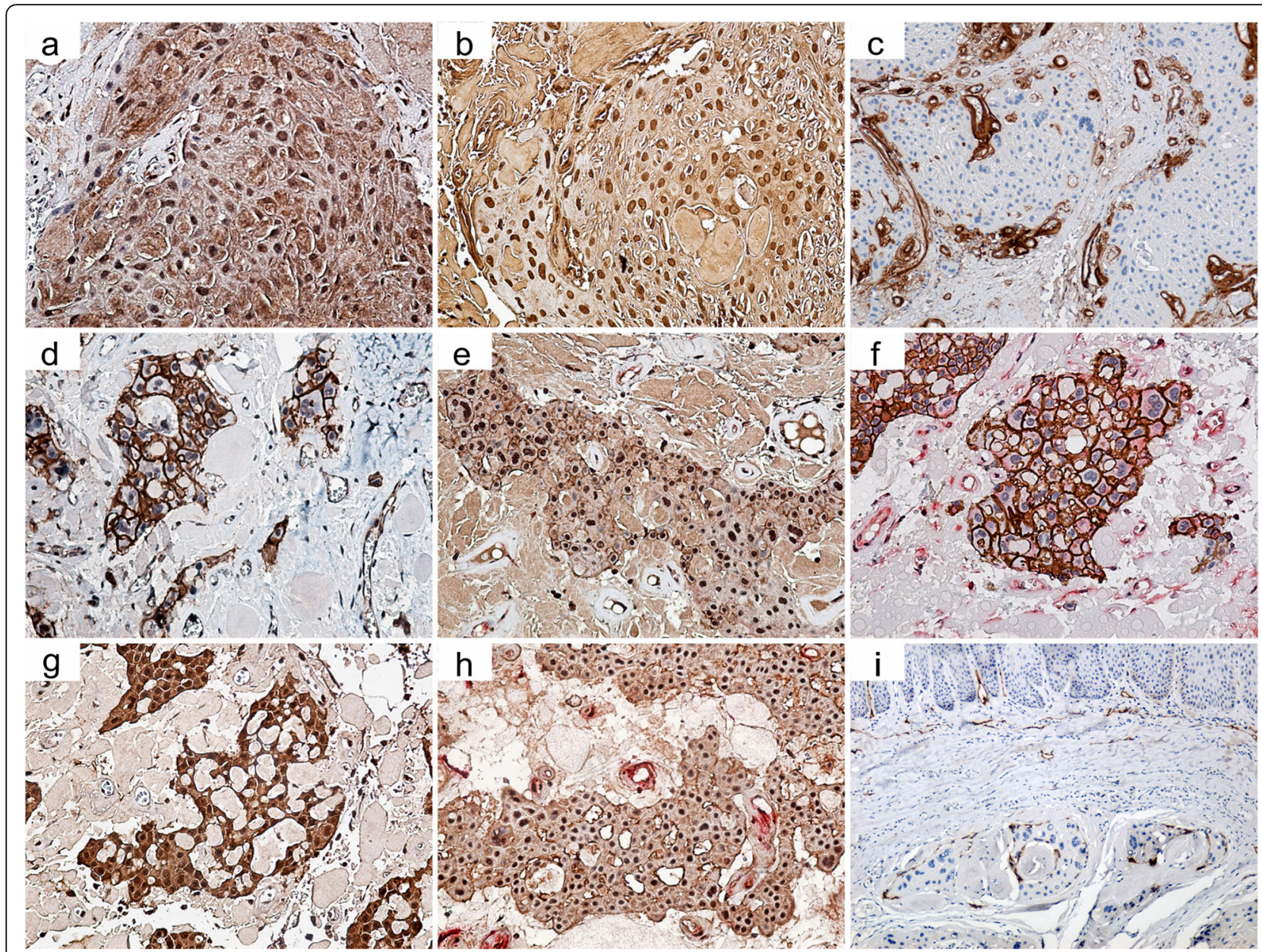

Fig. 3 Immunohistochemical patterns of the tumor. a-b Neoplastic epithelial cells with strong nuclear and cytoplasmic staining for MMP-3 and MMP-9 (immunostaining, original magnification $\times 20$ ). c Variable collagen IV reactivity around neoplastic epithelial proliferations (immunostaining, original magnification $\times 20$ ). $\mathbf{d}$ Neoplastic epithelial cells from tumor advancing edge with strong membrane and cytoplasmic staining for Beta-catenin (immunostaining, original magnification $\times 20$ ), e Neoplastic epithelial cells from tumor advancing edge with strong membrane and nuclear staining for $\mathrm{N}$-cadherin (immunostaining, original magnification $\times 20$ ). f Neoplastic epithelial cells from tumor advancing edge with E-cadherin (brown staining) and vimentin (red staining) cytoplasmic colocalization (double immunostaining, original magnification $\times 20$ ). $\mathbf{g}$ Neoplastic epithelial cells from tumor advancing edge with strong cytoplasmic and nuclear reactivity for Slug 1 (immunostaining, original magnification $\times 20$ ). $\mathbf{h}$ Neoplastic epithelial cells with strong membrane, cytoplasmic and nuclear reactivity for CXCR4 (double immunohistochemical detection CXCR4-brown staining and vimentin- red staining) (double immunostaining, original magnification $\times 20$ ). i Podoplanin tumor cell reactivity, with a membranous pattern at the advancing edge, mainly at the periphery of tumor proliferations (immunostaining, original magnification $\times 10$ )

roles, such as activation of some cancer-related signaling pathways that could promote tumor proliferation, and most likely invasion and metastasis [27]. Moreover, studying the collagen IV expression, we noticed absence or discontinuity in reactivity at the invasion front, a fact that could justify the local aggressiveness of the presented case. Other studies pointed out that collagen IV expression could be correlated with the growth and aggressiveness of odontogenic tumors [26, 28]. Thus MMP-9 and collagen IV could be useful markers in assessing the degree of local aggressiveness of these odontogenic tumors, including the CEOTs.

Investigating the epithelial-mesenchymal transition (EMT) process, we have found that tumor cells were reactive for all investigated cadherins, for Integrin $\beta 1$ and Beta-catenin with a gradual transition from the membranous pattern to a cytoplasmic pattern toward the advancing edge. In addition, we have observed even a nuclear reactivity for $\mathrm{N}$ - and $\mathrm{P}$-cadherin. Moreover, as a sign of active EMT, we found an increased cytoplasmic reactivity for vimentin and a prevailing nuclear Twist 1 and Slug 1 expression in tumor cells, especially at the tumor's advancing edge. Our results were confirmed in the literature by cases of ameloblastomas, where it was also been noticed an E-cadherin downregulation simultaneously with an upregulation of podoplanin, $\beta$-catenin, and CD44v6 at the tumor advancing edges, suggesting their involvement in mediating collective cell migration 
Table 2 Clinicopathological features of currently reported cases of CEOT involving the maxillary sinus

\begin{tabular}{|c|c|c|c|c|c|c|c|}
\hline Reference & Age & Gender & Teeth involvement & Maxillary bone involved & Extraosseous extension besides maxillary sinus & Microscopic features & Follow up \\
\hline Gon, 1965 [14] & 35 & Female & First molar & Right maxilla & No & Conventional & NP \\
\hline Stimson et al., 1968 [19] & 35 & Male & Third molar & Left maxilla & Left nasal fossa & NF & NF \\
\hline Lee et al., 1992 [16] & 27 & Female & Second premolar & Left maxilla & No & Conventional & 7 years. \\
\hline Bridle et al., 2006 [12] & 30 & Female & $\begin{array}{l}\text { Displacement of the second } \\
\text { premolar and first molar }\end{array}$ & Right maxilla & Displacement of the eye globe & Conventional & NP \\
\hline $\begin{array}{l}\text { Gopalakrishnan et al., } \\
2006 \text { [15] }\end{array}$ & 15 & Male & Second molar & Left maxilla & $\begin{array}{l}\text { Nasal cavity, narrowing and compressing } \\
\text { the inferior meatus }\end{array}$ & Cystic variant & 1 year \\
\hline $\begin{array}{l}\text { Mohtasham et al., } \\
2008 \text { [17] }\end{array}$ & 18 & Male & No & Right maxilla & None & Conventional & NP \\
\hline da Rosa et al., 2011 [13] & 33 & Female & No & Left maxilla & $\begin{array}{l}\text { Lateral wall of nasal cavity, soft tissue, } \\
\text { masseter, orbicularis oris, medial pterygoid }\end{array}$ & Conventional & NP \\
\hline Sahni et al., 2012 [4] & 52 & Male & No & Right maxilla & No & Conventional and clear cell & 3 years \\
\hline Müller et al., 2012 [18] & 36 & Male & No & Right maxilla & No & Conventional & 4 years \\
\hline Carrero et al., 2014 [20] & 69 & Male & Third molar & Left maxilla & No & Conventional & 8 years \\
\hline Foroughi et al., 2015 [21] & 34 & Female & No & $\begin{array}{l}\text { Recurrence in } \\
\text { left maxilla }\end{array}$ & $\begin{array}{l}\text { Orbit and ethmoidal air cells superiorly } \\
\text { and the nasal airway medially }\end{array}$ & Conventional & 8 years \\
\hline Rani et al., 2016 [22] & 48 & Female & No & Right maxilla & Connective tissue of oral mucosal & Conventional & 1 year \\
\hline Present case & 45 & Female & $\begin{array}{l}\text { Palatal ectopia of the } \\
\text { second molar }\end{array}$ & Left maxilla & Buccal vestibule mucosa & $\begin{array}{l}\text { Conventional with few clear cells } \\
\text { and cementum-like components }\end{array}$ & 0.6 years \\
\hline
\end{tabular}


and local invasiveness [29]. Moreover, it has been reported that transcription factors such as Snail, Slug, SIP1, and Twist could have differential roles in mediating local invasiveness in ameloblastomas [30]. Also, in the present study we have observed a podoplanin expression at the advancing edge, mainly at the periphery of tumor proliferations, suggesting its involvement in tumor invasiveness. In fact, it is well known that this transmembrane sialomucin is involved in odontogenesis and in promoting local invasion of various odontogenic tumors [29].

A series of studies reported the role of CXCR4 in modulation of cancer cells migration in several human malignancies, especially due to increase production of MMPs [31, 32]. Here we have observed membrane and nuclear CXCR4 reactivity in CEOT cells regardless of tumor topography (tumor center versus the advancing edge), suggesting the involvement of this chemokine in mediating locally tumor cell invasion or even a potential malignant evolution of this tumor.

However, despite its aggressive behavior, we found that less than $3 \%$ of tumor cells were positive to Ki-67, a value that falls within the range $(0.27-10 \%)$ reported by the literature for this kind of tumors [33]. Higher values were recorded in CEOTs with malignant transformation, with at least three-fold increase in the suspected malignant area compared to benign areas [11]. A reduced level of Ki-67 index together with the absence of any clinical finding of metastasis, with no vascular invasion or atypical mitotic figures, justifies the benign character of the tumor in the current case.

Summarizing our results we can conclude that the peculiar locally aggressive behavior of the presented case is the result of the involvement of multiple molecular mechanisms. Thus investigating such biomarkers could be useful in assessing the degree of local aggressiveness and even the malignant potential of these odontogenic tumors, suggesting also the most efficient type of therapeutical approach.

\section{Conclusions}

This case report describes the thirteenth known case of CEOT with maxillary sinus extension and the second one that also involves the buccal vestibule mucosa. Histopathologically, this case corresponds to an epithelium-rich CEOT variant, but with scattered S100+ clear cells and deposits of cementum-like material. The immunohistochemical investigation confirms its aggressive behavior by tumor overexpression of biomarkers involved especially in extracellular matrix degradation, cell adhesion and the EMT processes, and even a potential malignant evolution of this tumor. However, our case did not fulfill the other criteria of malignancy thus was deemed a benign tumor. A radical surgery resection with defect reconstruction was performed and after 12 months following the treatment there was no signs of recurrence.

\section{Abbreviations}

CEOT: Calcifying epithelial odontogenic tumor; CK: Cytokeratin; CT: Computed tomography; CXCR-4: Chemokine receptor type 4; EMT: Epithelial to mesenchymal transition; H \& E: Hematoxylin and eosin; MMP: Matrix metalloproteinase; PAS: Periodic acid-Schiff

\section{Acknowledgements}

The authors gratefully thank the patient for her cooperation.

Funding

There was no funding for this article.

Availability of data and materials

Data and materials of this work are available on request by the corresponding author.

\section{Authors' contributions}

Study concepts and study design: CIM, Data acquisition: CM, AC, AES. Quality control of data and algorithms: CIM, DNP. Data analysis and interpretation:

CIM, CM. Manuscript preparation: AC, AES. Manuscript editing: CM, AES. Manuscript review: CIM, Corresponding author: DP. All authors read and approved the final manuscript.

\section{Authors' information}

$\mathrm{CM}$ and $\mathrm{AC}$ : co-first author.

Competing interests

The authors declare that they have no competing interests.

\section{Consent for publication}

Written and informed consent was obtained from the patient for publication of this Case Report and any accompanying images.

\section{Ethics approval and consent to participate}

The study was approved by the Committee of Ethics and Academic and Scientific Deontology of the University of Medicine and Pharmacy of Craiova (reference number: 72/11.07.2016)

\section{Author details}

${ }^{1}$ Department of Oral \& Maxillofacial Surgery, University of Medicine and Pharmacy Craiova, Petru Rares 2, Craiova 200349, Romania. ${ }^{2}$ Department of Research Methodology, University of Medicine and Pharmacy Craiova, Petru Rares 2, Craiova 200349, Romania. ${ }^{3}$ Department of Pathology, University of Medicine and Pharmacy Craiova, Petru Rares 2, Craiova 200349, Romania.

Received: 2 August 2016 Accepted: 8 November 2016

Published online: 21 November 2016

\section{References}

1. Takata T, Slootweg PJ. Calcifying epithelial odontogenic tumour. In: Barnes LE WJ, Reichart P, Sidradinsky D, editors. Pathology and genetics head and neck tumors, vol. 5. Lyon: IARC Press; 2005. p. 302-3.

2. Thoma KH, Goldman HM. Odontogenic tumors: a classification based on observations of the epithelial, mesenchymal, and mixed varieties. Am J Pathol. 1946;22(3):433-71.

3. Pindborg JJ, Kramer IRH, Torloni H. Histological typing of odontogenic tumours, Jaw cysts, and allied lesions. International histological classification of tumours. 1st ed. Geneva: World Health Organization; 1971. p. 7.

4. Sahni P, Nayak MT, Singhvi A, Sharma J. Clear cell calcifying epithelial odontogenic (Pindborg) tumor involving the maxillary sinus: A case report and review of literature. J Oral Maxillofac Pathol. 2012;16(3):454-9.

5. Nakano H, Ota Y, Yura Y. Calcifying epithelial odontogenic tumor of the maxilla with ulcerative stomatitis: a case report. Br J Oral Maxillofac Surg. 2009:47(3):222-4.

6. Nelson SR, Schow SR, Read LA, Svane TJ. Treatment of an extensive calcifying epithelial odontogenic tumor of the mandible. J Oral Maxillofac Surg. 1992;50(10):1126-31.

7. Bouckaert MM, Raubenheimer EJ, Jacobs FJ. Calcifying epithelial odontogenic tumor with intracranial extension: report of a case and review of the literature. Oral Surg Oral Med Oral Pathol Oral Radiol Endod. 2000;90(5):656-62. 
8. Demian N, Harris RJ, Abramovitch K, Wilson JW, Vigneswaran N. Malignant transformation of calcifying epithelial odontogenic tumor is associated with the loss of p53 transcriptional activity: a case report with review of the literature. J Oral Maxillofac Surg. 2010;68(8):1964-73.

9. Franklin $C D$, Pindborg JJ. The calcifying epithelial odontogenic tumor. A review and analysis of 113 cases. Oral Surg Oral Med Oral Pathol. 1976;42(6):753-65.

10. More CB, Vijayvargiya R. Intraosseous calcifying epithelial odontogenic (Pindborg) tumor: a rare entity. J Oral Maxillofac Pathol. 2015;19(2):269.

11. Zhong Y, Wang L, Li T, Chen XM. Calcifying epithelial odontogenic tumour showing malignant transformation: a case report and review of the literature. Chin J Dent Res. 2010;13(2):157-62.

12. Bridle C, Visram K, Piper K, Ali N. Maxillary calcifying epithelial odontogenic (Pindborg) tumor presenting with abnormal eye signs: case report and literature review. Oral Surg Oral Med Oral Pathol Oral Radiol Endod. 2006;102(4):e12-5.

13. da Rosa MR, de Oliveira JM, Dias-Ribeiro E, Ferreira-Rocha J, de Barros IM, Lopes PM. Large calcifying epithelial odontogenic tumor with extension into the maxillary sinus: a case report. Gen Dent. 2011;59(1):e38-40.

14. Gon F. The calcifying epithelial odontogenic tumour: report of a case and a study of its histogenesis. Br J Cancer. 1965;1939-50.

15. Gopalakrishnan R, Simonton S, Rohrer MD, Koutlas IG. Cystic variant of calcifying epithelial odontogenic tumor. Oral Surg Oral Med Oral Pathol Oral Radiol Endod. 2006;102(6):773-7.

16. Lee CY, Mohammadi H, Mostofi R, Habibi A. Calcifying epithelial odontogenic tumor of the maxillary sinus. J Oral Maxillofac Surg. 1992;50(12):1326-8.

17. Mohtasham N, Habibi A, Jafarzadeh H, Amirchaghmaghi M. Extension of Pindborg tumor to the maxillary sinus: a case report. J Oral Pathol Med. 2008;37(1):59-61.

18. Muller D, Manojlovic S, Luksic I, Grgurevic J. Calcifying epithelial odontogenic tumor of the maxilla (Pindborg tumor). Coll Antropol. 2012;36 Suppl 2:205-8.

19. Stimson $P G$, Luna MA, Butler JJ. Seventeen-year history of a calcifying epithelial odontogenic (Pindborg) tumor. Oral Surg Oral Med Oral Pathol. 1968;2:5204-8.

20. Carrero M, Junquera L, Carlos de Vicente J, Fresno F. Extension of calcifying epithelial odontogenic tumor to the maxillary sinus: a case report. Open J Stomatol. 2014:4:280-4.

21. Foroughi R, Amini Shakib P, Babaei Darzi A, Seyedmajidi M, Jamaatlou N. Calcifying epithelial odontogenic tumor: report of a recurrent destructive case with review of literature. J Dent (Tehran). 2015;12(1):78-84.

22. Rani V, Masthan MK, Aravindha B, Leena S. Aggressive calcifying epithelial odontogenic tumor of the maxillary sinus with extraosseous oral mucosal involvement: a case report. Iran J Med Sci. 2016:41(2):145-9.

23. Sadeghi EM, Hopper TL. Calcifying epithelial odontogenic tumor. J Oral Maxillofac Surg. 1982;40(4):225-9.

24. Philipsen HP, Reichart PA. Calcifying epithelial odontogenic tumour: biological profile based on 181 cases from the literature. Oral Oncol. 2000;36(1):17-26.

25. Poomsawat S, Punyasingh J. Calcifying epithelial odontogenic tumor: an immunohistochemical case study. J Mol Histol. 2007;38(1):103-9.

26. Henriques AC, Vasconcelos MG, Galvao HC, de Souza LB, de Almeida Freitas R. Comparative analysis of the immunohistochemical expression of collagen IV, MMP-9, and TIMP-2 in odontogenic cysts and tumors. Oral Surg Oral Med Oral Pathol Oral Radiol Endod. 2011;112(4):468-75.

27. Mannello F, Medda V. Nuclear localization of matrix metalloproteinases. Prog Histochem Cytochem. 2012:47(1):27-58.

28. Grewal HK, Sethi S. Immunohistochemical expression of Type IV collagen and autocrine motility factor receptor in odontogenic tumours. J Clin Diagn Res. 2014;8(10):ZC17-21.

29. Siar CH, Ishak I, Ng KH. Podoplanin, E-cadherin, beta-catenin, and CD44v6 in recurrent ameloblastoma: their distribution patterns and relevance. J Oral Pathol Med. 2015;44(1):51-8.

30. Siar CH, Ng KH. Differential expression of transcription factors Snail, Slug SIP1, and twist in ameloblastoma. J Oral Pathol Med. 2014;43(1):45-52.

31. Ehtesham M, Winston JA, Kabos P, Thompson RC. CXCR4 expression mediates glioma cell invasiveness. Oncogene. 2006;25(19):2801-6.

32. Singh S, Singh UP, Grizzle WE, Lillard Jr JW. CXCL12-CXCR4 interactions modulate prostate cancer cell migration, metalloproteinase expression and invasion. Lab Invest. 2004;84(12):1666-76.

33. Azevedo RS, Mosqueda-Taylor A, Carlos R, Cabral MG, Romanach MJ, de Almeida OP, et al. Calcifying epithelial odontogenic tumor (CEOT): a clinicopathologic and immunohistochemical study and comparison with dental follicles containing CEOT-like areas. Oral Surg Oral Med Oral Pathol Oral Radiol. 2013;116(6):759-68.

\section{Submit your next manuscript to BioMed Central and we will help you at every step:}

- We accept pre-submission inquiries

- Our selector tool helps you to find the most relevant journal

- We provide round the clock customer support

- Convenient online submission

- Thorough peer review

- Inclusion in PubMed and all major indexing services

- Maximum visibility for your research

Submit your manuscript at www.biomedcentral.com/submit
Biomed Central 